\title{
Role of stromal-epithelial interactions in hormonal responses*
}

\author{
Gerald R. Cunha', Paul S. Cooke ${ }^{2}$, and Takeshi Kurita ${ }^{1,3}$ \\ ${ }^{\prime}$ Department of Anatomy, University of California, San Francisco, CA; ${ }^{2}$ Department of Veterinary Biosciences \\ and Division of Nutritional Sciences, University of Illinois, Urbana, IL, USA; and ${ }^{3}$ Department of Cancer \\ Endocrinology, BC Cancer Agency, Vancouver, BC, Canada
}

\begin{abstract}
Summary. Steroid sex hormones (17 $\beta$-estradiol, testosterone, dihydrotestosterone, and progesterone) and aryl hydrocarbons such as the dioxins regulate epithelial proliferation and secretory protein production and differentiation in their respective target organs in male and female urogenital tracts and mammary glands. Recent evidence has demonstrated that stromal-epithelial interactions are critical for mediating the effects of these molecules on epithelial cells. Our results have indicated that estradiol, testosterone, progesterone, and dioxin regulate epithelial proliferation (stimulation or inhibition) via paracrine mechanisms requiring the appropriate receptor in the stroma. The androgen receptor $(A R)$, estrogen receptor alpha $(\mathrm{ER} \alpha)$, progesterone receptor $(\mathrm{PR})$, or aryl hydrocarbon receptor (AhR) in the epithelium are neither necessary nor sufficient for the regulation of epithelial proliferation. Moreover, during prostatic development, signaling through the stromal $A R$ is required to induce prostatic epithelial identity, ductal morphogenesis and glandular differentiation. Epithelial functional differentiation is regulated in the prostate, uterus, and vagina via AR (prostate) and ER $\alpha$ (uterus and vagina). In these organs both epithelial and stromal steroid receptors are required for steroidal regulation of certain aspects of epithelial differentiation such as epithelial secretory protein production in the uterus and epithelial cornification in the vagina and
\end{abstract}

Received November 8, 2004

*This work was supported by NIH grants CA84294, CA89520, CN-35115, CA91967, DK58105 (to GRC), and AG15500 (to PSC).

Address for correspondence: Prof. Gerald R. Cunha, University of California, $3^{\text {rd }}$ and Parnassus, Department of Anatomy, HSW 1323, San Francisco, CA 94143 USA

Phone: +1-415-476-4140, Fax: +1-415-502-2270

E-mail: grcunha@itsa.ucsf.edu prostate (squamous metaplasia). The mechanistic basis of these stromal-epithelial interactions is poorly understood, but growth factors appear to be mediators of these cell-cell interactions.

\section{Introduction}

Organs of the male and female urogenital tracts and mammary gland consist of an epithelial parenchyma and associated fibromuscular stroma. In the adult uterus, the luminal epithelium, associated glands and stroma comprise the endometrium, which is in turn surrounded by the myometrium. In the adult prostate, sleeves of smooth muscle cells and fibroblasts surround the epithelial ducts. The development of organs composed of an epithelial parenchyma is dependent on reciprocal mesenchymalepithelial interactions. Indeed, morphogenesis and differentiation of both the epithelium and mesenchyme are abortive if the epithelium and mesenchyme are grown separately (Marker et al., 2003). Paracrine signals from the mesenchyme initially induce and specify epithelial identity, e.g., whether the epithelium will differentiate as a uterus, vagina or prostate (Cunha et al., 1998). Second, the mesenchyme induces and specifies the morphological form or pattern of the epithelium, that is, whether the epithelium will form a simple vesicle (bladder), whether it will form a branched ductal network (prostate or mammary gland), whether it will form a large unbranched tube (vagina) or a tube with glandular evaginations (uterus). Third, during the course of epithelial morphogenesis the mesenchyme regulates epithelial proliferation in a highly coordinated fashion to generate specific epithelial patterns (Marker et al., 2003). Fourth, the mesenchyme specifies functional differentiation. This includes specifying the types of epithelial secretory proteins produced or the expression of specific cytoskeletal or membrane proteins (keratins and uro- 
plakins) (Cunha et al., 1992; Hayward, 1992; Kurita et al., 2001a). Fifth, during development and in adulthood epithelial apoptosis is an important biological mechanism in which the occupancy status of the stromal androgen receptor (AR) in the prostate and stromal progesterone receptor $(\mathrm{PR})$ in the uterus plays a key role in regulating epithelial apoptosis (Kurita et al., 2001b).

Tissue recombination experiments have revealed that interactions between the developing mesenchyme and epithelium are reciprocal. For example, if the epithelium of the uterus is ablated in vivo, the stromal cells no longer undergo decidualization in response to estrogen plus progesterone (Lejeune et al., 1981). This finding indicates that the epithelium is providing at least a permissive signal that allows the normal stromal response to hormone treatment. Subsequent work by Bigsby showed that, under progesterone dominance, the epithelium elaborates factors that stimulate the underlying stroma to proliferate when estrogen is administered. Through the use of tissue recombinants uterine, but not vaginal, epithelium paired with uterine stroma allowed stromal cell proliferation in response to estradiol plus progesterone, indicating specificity in the epithelial signal that permitted the stromal proliferative response (Bigsby, 2002).

Since the development, growth, and function of male and female reproductive tracts are dependent upon reciprocal stromal-epithelial interactions in addition to being regulated by steroid sex hormones, it is reasonable to investigate hormone action in male and female reproductive tracts in the context of receptor-mediated events in which epithelial versus stromal receptors may play specific roles. This approach has been made possible with the availability of mutant mice null for the androgen receptor (AR), estrogen receptor alpha $(\mathrm{ER} \alpha)$, estrogen receptor alpha $(\mathrm{ER} \beta)$, progesterone receptor (PR), and aryl hydrocarbon receptor (AhR).

Investigation of AR null Tfm (testicular feminization) mice has revealed that development of the prostate and other male accessory sexual organs is dependent upon signaling through the AR (Ohno, 1979), that is, male AR null mutant mice fail to develop any masculine accessory sex organs. Conversely, embryonic development of the uterus and other female reproductive organs is normal in ER $\alpha$ knockout ( $\alpha$ ERKO) mice (Lubahn et al., 1993). However, postnatal differentiation, growth, and function of the uterus (and other estrogen target organs) during the juvenile period and adulthood are impaired in ERKO $\alpha$ mice (Couse and Korach, 1999). Investigation of PR knockout (PRKO) mice reveals normal embryonic development of the female genital tract, even though progesterone signaling through the PR is essential in the mature uterus during the estrous cycle and during the establishment and maintenance of pregnancy and lactogenesis of the mammary gland (Lydon et al., 1996; Lydon et al., 1995). Likewise, the AhR knockout (AhRKO) mouse provides a useful tool for producing tissue recombinants lacking $\mathrm{AhR}$ in one or more tissue compartment and for investigating the mechanism by which AhR agonists inhibit uterine epithelial proliferation (Lin et al., 2002). Thus, the profound phenotypes of these receptor mutant mice have provided the means for testing the relative roles of epithelial versus stromal steroid receptors in hormone action in male and female reproductive organs.

An understanding of the mechanisms by which androgens, estrogens, progestins and dioxins elicit effects in reproductive tissues is important for the following reasons: a) the critical role of these hormones in normal differentiation and function; b) their involvement in the etiology and progression of various pathologies; c) potential effects of environmental exposure to estrogenic, androgenic, antiestrogenic and anti-androgenic compounds as well as AhR agonists; and d) the increased use of drugs which modulate the signaling systems for androgens, estrogens, and progestins. Evidence indicates that interactions between the stroma and epithelium in adult organs or between mesenchyme, the undifferentiated embryonic/fetal precursor of stroma, and the embryonic epithelium are critical for mediating the effects of estrogenic, androgenic, and progestational agents. Indeed, many effects of these hormones on male and female reproductive tract epithelium are mediated totally or in part through the appropriate receptors in the stroma (Cooke et al., 1998; Cunha et al., 1998). In this review we focus on the stromal-epithelial interactions involved in normal and abnormal hormonal responses in male and female hormone target organs. Stromal-epithelial interactions are reciprocal, so the role of the epithelium in regulating stroma will also be considered.

\section{Model systems for studying the mechanism of the effects of hormones and dioxins on reproductive epithelium}

Genetic engineering of mice in which a specific gene has been inactivated or "knocked out" provides a versatile and powerful tool for examining the role of specific genes and their corresponding proteins. In the field of steroid receptor biology, the spontaneous AR-null Tfm mouse has been critical in our understanding the role of the AR in masculine development (Ohno, 1979). The development of the $\alpha \mathrm{ERKO}$ mouse (Lubahn et al., 1993), in which the ER $\alpha$ gene has been rendered non-functional by gene targeting, has defined the phenotypic and functional consequences of an absence of ER $a$ (Couse and Korach, 1999). Similarly, PRKO and 


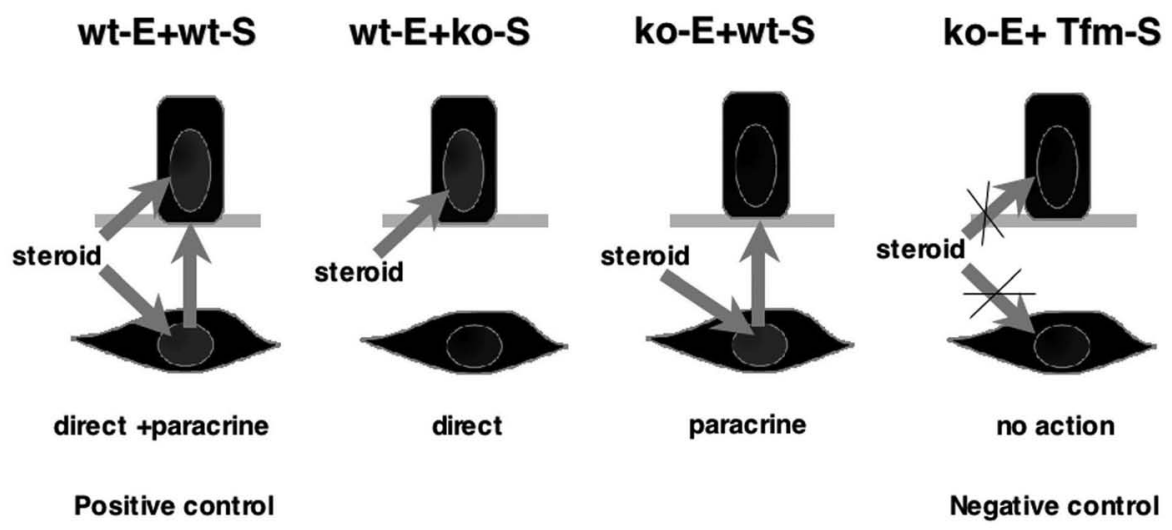

Fig. 1. Diagram of a general strategy for assessing the respective roles of epithelial versus stromal (mesenchy$\mathrm{mal}$ ) hormones receptors in hormonal response. Organ rudiments of wild-type (wt) and receptor knockout (KO) mice are separated into their stromal $(\mathrm{S})$ and epithelial (E) components which are recombined to generate the four possible tissue recombinants (KO-S+KO-E, KO-S+wt-E, wt-S+KO-E and wt-S+wt-E). The resultant tissue recombinants are grown in appropriate hosts to allow organogenesis and functional differentiation. The hosts can then be subjected to specific hormonal challenges. The wt-S+wt-E tissue recombinant provides a positive control. The KO-S+KO-E tissue recombinant provides a negative control. The KO-S+wt-E and wt-S+KO-E tissue recombinants provide the means for assessing the respective roles of epithelial versus stromal receptors.

AhRKO mice have provided similar tools to explore the role of the $\mathrm{PR}$ and $\mathrm{AhR}$ in various aspects of reproductive development and function (Lydon et al., 1995, 1996; Schmidt et al., 1996).

Over the years we have used an experimental system that utilizes tissues from steroid receptor and aryl hydrocarbon receptor knockout mice to study the mechanism of androgen, estrogen, progesterone, and dioxin action in male and female genital tracts and the mammary gland. The crucial feature of this system involves enzymatically separating and recombining the sepithelium (E) and stroma (S) from a receptor knockout $(\mathrm{KO})$ mouse with that of the wild-type (wt) mouse, which expresses a receptor (Fig. 1). This method makes it possible to experimentally control the hormone receptor status of both the stroma and epithelium by preparing tissue recombinations that lack a receptor in both stromal and epithelial compartments (KO-S+KO-E), express a receptor in either the epithelium or stroma (KOS+wt-E and wt-S+KO-E), or express a receptor in both the epithelium and stroma (wt-S+wt-E). These tissue recombinants are then grafted into host animals, and their responsiveness to the test hormone examined. By analyzing the effects of a lack of stromal and/or epithelial receptors on epithelial hormonal response such as epithelial mitogenesis or secretory protein production, the role of steroid receptors in each tissue compartment can be definitively determined.

\section{The effect of androgens on embryonic mouse mammary gland development}

Klaus Kratochwil was the first to carry out tissue recombination experiments on hormone action in his study of androgen-induced regression of the embryonic mammary rudiment (Kratochwil and Schwartz, 1976). Embryonic murine mammary buds develop in both male and female fetuses, but regress in males. In most mouse strains fetal testicular androgens elicit condensation of the mesenchyme around male mammary buds and trigger destruction of the epithelial rudiment through reciprocal interactions between the epithelium and mesenchyme (Kratochwil, 1987). The embryonic mouse mammary gland is initially unresponsive to testosterone at E11 and E12, becomes responsive to testosterone at E13, and completes regression by E16 (Kratochwil, 1977). Acquisition of sensitivity to testosterone correlates temporally with the expression of the AR in the mammary mesenchyme at 12 days of gestation (Kratochwil and Schwartz, 1976) when the mammary epithelial bud becomes surrounded by a population of AR-positive mesenchymal cells (Heuberger et al., 1982). The presence of mesenchymal AR and the corresponding absence of epithelial AR suggests that the embryonic mammary bud is destroyed by testosterone-activated mesenchymal cells 


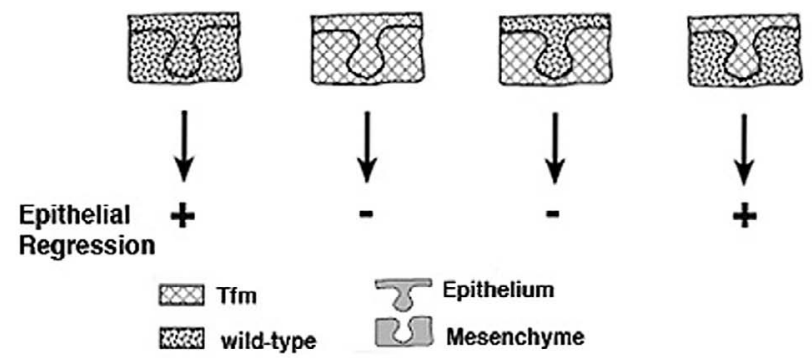

Fig. 2. Summary of studies of androgen-induced regression of the embryonic mouse epithelial mammary rudiment. Tissue recombinants were constructed with wild-type and AR-negative Tfm mammary epithelia and mesenchymes as indicated. All tissue recombinants were exposed to testosterone in vitro. Epithelial regression occurred in both the wild-type mesenchyme+ wild-type epithelium and the wild-type mesenchyme $+\mathrm{Tfm}$ epithelium recombinants, indicating that androgen-induced regression of the embryonic mouse epithelial mammary rudiment is mediated via paracrine effects downstream of the binding of testosterone to mesenchyme AR. (Redrawn from Kratochwil and Schwartz, 1976).

rather than by direct hormone action.

The apposition of AR-positive mesenchymal cells around the embryonic mammary epithelial bud suggests that either the mammary epithelium attracts preexisting AR-positive mesenchymal cells or that the epithelium induces AR expression in the surrounding mesenchyme. These possibilities were tested in tissue recombination studies in which the AR-negative inter-bud mesenchyme (dermis) was associated with the embryonic mammary, lung, or salivary gland epithelium. The resulting tissue recombinations were grown in vitro and assessed for AR expression. The mammary bud epithelium consistently induced AR in the inter-bud mesenchyme (which is normally AR-negative), and thus the mammary buds became surrounded by an AR-positive mesenchyme. This induction of mesenchymal AR only occurred when mammary epithelium was used and not when epithelia of the salivary gland or lung were combined with inter-bud mesenchyme (Dürnberger and Kratochwil, 1980). Thus, the mammary epithelium specifically induced the expression of ARs in adjacent mesenchymal cells.

The question of whether testosterone elicited mammary epithelial regression by direct action on the epithelium or by paracrine action mediated by mesenchymal AR was answered by analysis of tissue recombinants composed of mammary gland epithelium and mesenchyme of wt and AR null Tfm (testicular feminization, Tfm) mice. Tfm mice have a point mutation in the gene encoding the AR ( $\mathrm{He}$ et al., 1991), fail to express a functional AR, and consequently are insensitive to androgens. Accordingly, endogenous or exogenous androgens cannot elicit regression of mammary glands of embryonic male Tfm mice. Durnberger and Kratochwil analyzed the four possible mammary tissue recombinations composed of wt and Tfm epithelium (E) and mesenchyme (M). Testosterone elicited destruction of the mammary epithelium only in tissue recombinations prepared with wt $(\mathrm{AR}+)$ mesenchyme (wt-M+wt-E and wt$\mathrm{M}+\mathrm{Tfm}-\mathrm{E}$ ), and not when AR negative Tfm mesenchyme was used (Tfm-M+Tfm-E and Tfm-M+wt-E) (Dürnberger and Kratochwil, 1980) (Fig. 2). These data conclusively demonstrated that androgens elicit embryonic mammary epithelial regression via the AR-positive mesenchyme, which in response to androgens is induced to condense around the epithelium, thus triggering epithelial regression (Durnberger and Kratochwil, 1980).

\section{Androgenic effects are mediated via mesenchymal-epithelial interactions during prostatic development}

Androgenic effects on prostatic development are mediated via ARs through mesenchymal-epithelial interactions. During fetal development ARs are initially detected solely in the urogenital sinus mesenchyme prior to and during prostatic bud formation. ARs are undetectable in developing prostatic buds suggesting that mesenchymal (but not epithelial) AR play a critical role in the early phases of prostatic development (Cooke et al., 1991; Takeda et al., 1991). To reveal the respective roles of epithelial versus mesenchymal ARs in prostatic development, prostatic tissue recombinants were prepared with urogenital sinus mesenchyme (M) and urogenital sinus epithelium (E) from ARpositive wt and AR-deficient Tfm mice (Fig. 3) (Cunha et al., 1987). As expected, tissue recombinants composed of $\mathrm{Tfm}-\mathrm{M}+\mathrm{Tfm}-\mathrm{E}$ did not form a prostate even in the presence of androgens. As a positive control, wt-M+wt-epithelium tissue recombinants formed a prostate in response to androgens. Tfm-M+wt-E tissue recombinants did not undergo prostatic development in the presence of androgens. This suggested a critical role of mesenchymal AR in prostatic development, which was confirmed in the reciprocal wtM+Tfm-epithelium tissue recombinant in which AR-deficient Tfm epithelium underwent prostatic development in association with AR-positive wt urogenital sinus mesenchyme. Significantly, in wt-M+Tfm-epithelium tissue recombinants the AR-deficient Tfm epithelium underwent androgen-dependent ductal morphogenesis, epithelial proliferation and columnar cytodifferentiation, thus forming a glandular epithelium resembling the prostate (Cunha and 

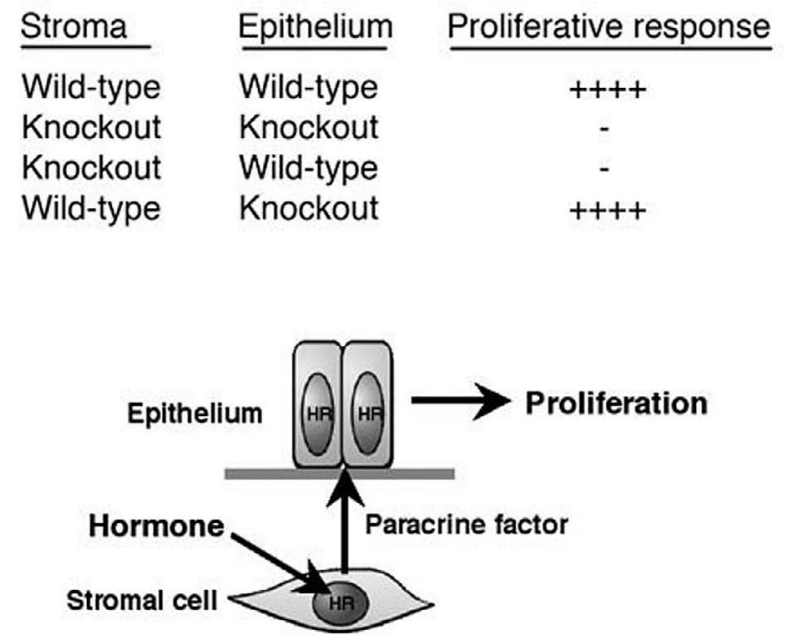

Fig. 3. Stimulation of epithelial proliferation in androgen target organs (prostate) and estrogen target organs (uterus and vagina). For the prostate, a proliferative response to testosterone was analyzed in tissue recombinants composed of wild-type (ARpositive) and Tfm (AR-negative) epithelium and mesenchyme. For estrogen target organs, a proliferative response to estradiol was analyzed in uterine and vaginal tissue recombinants prepared with wild-type (ER $\alpha$-positive) and $\alpha \operatorname{ERKO}$ (ER $\alpha$-negative) epithelium and mesenchyme. Results given in the table indicate (see figure) that testosterone and estradiol stimulate epithelial proliferation via paracrine influences downstream of the binding of hormones (testosterone or estradiol) to mesenchy$\mathrm{mal} / \mathrm{stromal}$ hormone receptors (HR) as appropriate.

Lung, 1978) (Fig. 3). Epithelial proliferation was examined specifically in wt-M+Tfm-epithelium tissue recombinants and was shown to be induced by testosterone to levels comparable to that in wt-M+wt-epithelium tissue recombinants. From these experiments it was concluded that prostatic epithelial proliferation is regulated via stromal and not epithelial ARs (Sugimura et al., 1986). These experiments were the first to demonstrate that many "androgenic effects" on prostatic epithelial development did not require epithelial ARs, but instead were elicited by the paracrine action of an AR-positive mesenchyme. This seminal experiment established the importance of paracrinology in the field of endocrinology, but it raised the question of the function of epithelial androgen receptors in organs such as the prostate and seminal vesicle. Further analysis of Tfm/wild-type tissue recombinants has revealed that epithelial ARs are required for the expression of AR-dependent secretory proteins (Cunha and Young, 1991; Donjacour and Cunha, 1993).

\begin{tabular}{|c|c|c|}
\hline Fat Pad & Epithelium & Proliferative response \\
\hline Wild-type & Wild-type & ++++ \\
\hline Knockout & Knockout & + \\
\hline Knockout & Wild-type & + \\
\hline Wild-type & Knockout & ++++ \\
\hline
\end{tabular}

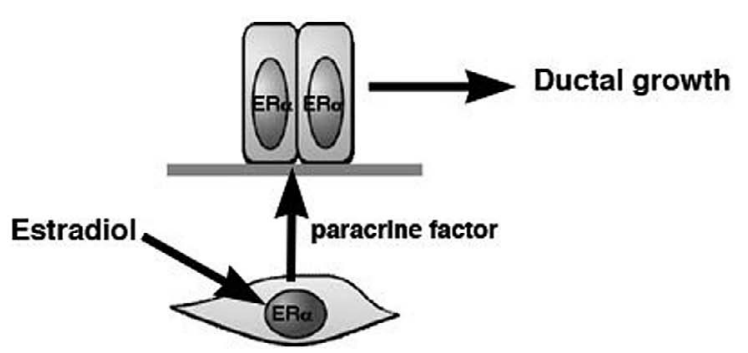

Fig. 4. Stimulation of mammary ductal growth by estradiol. Mammary tissue recombinants were prepared with wild-type (ER $\alpha$-positive) and $\alpha$ ERKO (ER $\alpha$-negative) mammary epithelium and fat pad. Results given in the table indicate (see figure) that estradiol stimulates mammary ductal growth via paracrine influences downstream of the binding of estradiol to ER $a$ in the fat pad (stroma).

\section{Estradiol induces epithelial proliferation indirectly through stromal ER $\alpha$ in the mouse reproductive tract}

Once the $\alpha$ ERKO mouse became available, the tissue recombination system was used to determine the respective roles of stromal versus epithelial ER $\alpha$ in estradiol-induced uterine epithelial proliferation. The original $\alpha \mathrm{ERKO}$ mouse engineered by Lubahn et al (Lubahn et al., 1993) has been shown to be able to produce truncated forms of ER $a$ (Dupont et al., 2000) and in a strict sense may not merit the designation of truly ER $a$ null. Nonetheless, this original $\alpha$ ERKO mouse is profoundly insensitive to estrogen stimulation, and a more recently engineered $\alpha$ ERKO mouse completely devoid of ER $\alpha$ has revealed few additional phenotypes (Dupont et al., 2000). Accordingly, uteri from the original $\alpha$ ERKO mice and wt mice were separated into epithelial and stromal components, and the following tissue recombinations were prepared: wt-S+wt-E; wt-S+aERKOE; $\alpha$ ERKO-S+wt-E and $\alpha$ ERKO-S $+\alpha$ ERKO-E. Tissue recombinants were transplanted under renal capsules of intact adult female nude mice and grown for 1 month. Then all hosts were ovariectomized. 


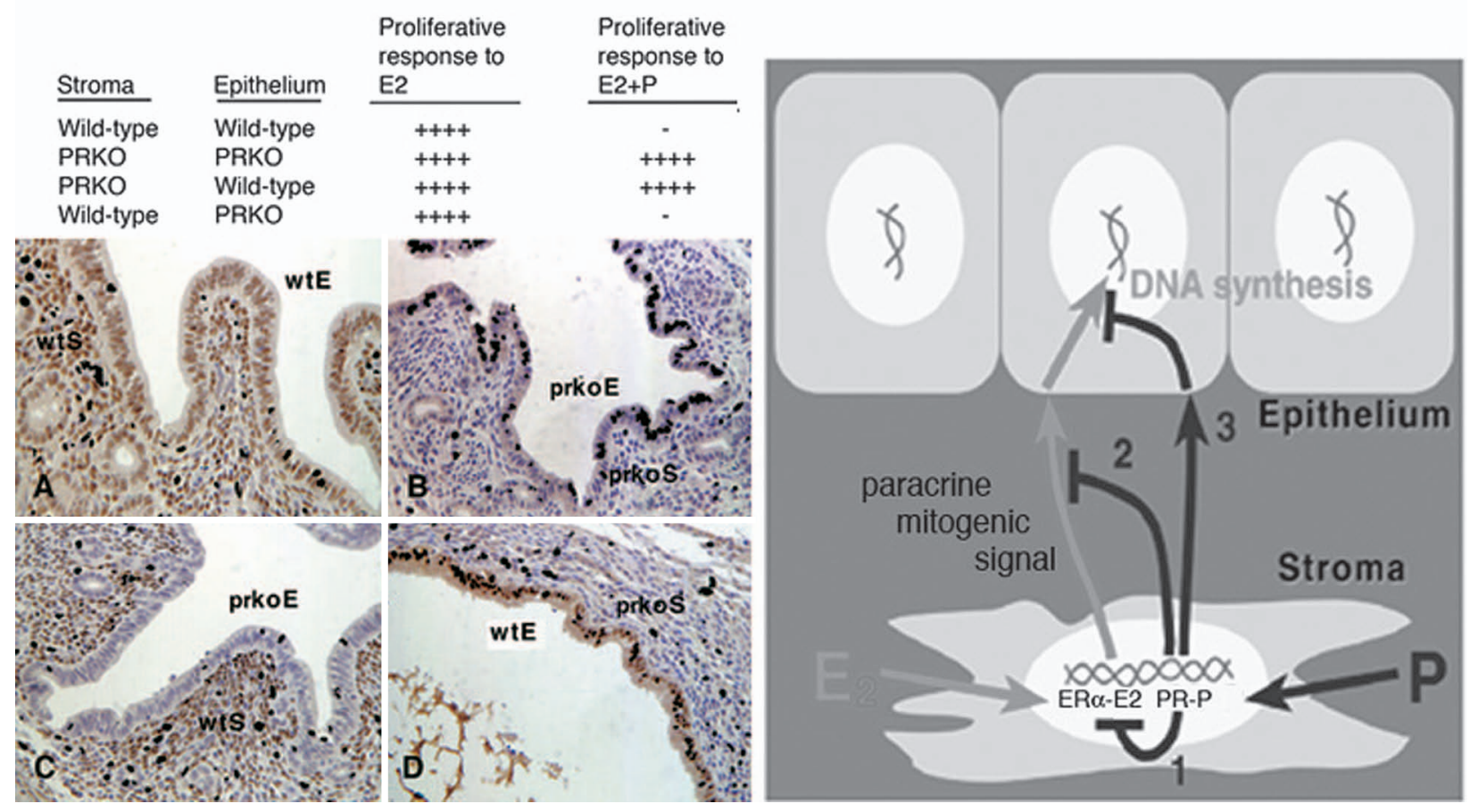

Fig. 5. Progesterone inhibition of estrogen-induced uterine epithelial proliferation. Uterine tissue recombinants were prepared with wild-type (PR-positive) and PRKO (PR-negative) epithelium and stroma as indicated in the table (upper left). The immunohistochemical images are tissue recombinants composed of A) wild-type stroma (wtS) + wild-type epithelium (wtE), B) prko stroma (prkoS) + prko epithelium (prkoE), C) wild-type stroma (wtS) + prko epithelium (prkoE), and D) prko stroma $($ prkoS $)+$ wild-type epithelium (wtE). The tissue recombinants were treated with estradiol plus progesterone as described (Kurita, 1998). Epithelial labeling with 3H-thymidine (black nuclei) has been inhibited by progesterone in $\mathbf{A}$ (the wtS+wtE positive control) and in $\mathbf{C}$ (the wtS+ prkoE recombinant), but not in $\mathbf{B}$ (the prkoS+prko negative control) or in D (the prkoS+wtE recombinant). Staining in A-D is for the progesterone receptor (brown) with hematoxilyn counterstain. The cartoon (right) indicates that estradiol (E) stimulates uterine epithelial proliferation via paracrine influences. Estrogeninduced uterine epithelial proliferation is inhibited by progesterone $(\mathrm{P})$ actions mediated via $\mathrm{PR}$ in the stroma. There are several mechanistic scenarios: 1) Progesterone may act within the stroma cell to prevent elaboration of the estrogeninduced trophic factor, 2) Progesterone may induce the synthesis and secretion of a factor that can neutralize the estrogeninduced trophic factor in the extracellular compartment, 3) Progesterone may induce the synthesis and secretion of a paracrine factor (such as TGF $\beta$ ) that upon reception by the epithelial cell inhibits uterine epithelial proliferation.

To examine the effects of estradiol on epithelial proliferation in uterine tissue recombinants, seven days after ovariectomy, half of the hosts were treated with estradiol while the other half were given an oil vehicle. The epithelial labeling index with ${ }^{3} \mathrm{H}$-thymidine or Ki-67was then determined. These studies demonstrated that an ER $\alpha$-negative epithelium can synthesize DNA and proliferate in response to estradiol when associated with an ER $\alpha$-positive stroma (Cooke et al., 1997). The epithelial labeling index in tissue recombinants composed of wt-S+wt-E and wt-S $+a$ ERKO-E increased several fold (and comparably) by estra- diol treatment (Fig. 3). In contrast, $a$ ERKO-S+wt-E and $\alpha$ ERKO-S $+\alpha$ ERKO-E uterine tissue recombinants failed to respond to estradiol and had low epithelial labeling following estradiol and oil treatment (Fig. 3). Thus, estradiol did not stimulate epithelial proliferation in tissue recombinants lacking the stromal $\operatorname{ER} \alpha$, even when the epithelial ER $\alpha$ was present. Taken together, these results indicate that epithelial ER $\alpha$ was neither necessary nor sufficient to mediate the proliferative response to estradiol, while the stromal ER $\alpha$ was obligatory. Comparable results were obtained in vaginal tissue recombinants in which the 
proliferative effect of estradiol was mediated by stromal and not epithelial ER $a$ (Fig. 3) (Buchanan et al., 1998a).

Recent work by Bigsby et al has confirmed that stromal $\operatorname{ER} \alpha$ alone is sufficient for maximal epithelial proliferation in response to estradiol, in that wt-S $+\alpha$ ERKO-E tissue recombinants expressed epithelial proliferation equal to that seen in wt-S+wt-E tissue recombinants (Bigsby et al., 2004). However, these investigators reported that epithelial proliferation in $\alpha$ ERKO-S+wt-E tissue recombinants from hosts given estradiol was somewhat increased compared with either $\alpha$ ERKO-S+wt-E tissue recombinants from oiltreated hosts or $\alpha$ ERKO-S $+\alpha$ ERKO-E tissue recombinants from either E2- or oil-treated hosts. However, the epithelial proliferative response to estradiol in the $\alpha$ ERKO-S+wt-E tissue recombinants was far less than the epithelial proliferation seen in either wt-S $+\alpha$ ERKO-E or wt-S+wt-E tissue recombinants in the same response. The stroma used in these studies was obtained from neonatal mice, and then the tissue recombinants were grown for 8-9 weeks, as opposed to the 5-week growth period used with the grafts in our studies. Bigsby et al suggest that this longer growth period may result in the epithelium becoming more mature and differentiated, and that this may allow a partial proliferative response in the epithelium mediated directly through ER $\alpha$ in that tissue (Bigsby et al., 2004). Therefore, although Cooke et al. (1997) and Bigsby et al. (2004) show that stromal ER $\alpha$ is both necessary and sufficient to mediate the full epithelial mitogenic response to estradiol, direct epithelial effects of estradiol may be capable of inducing limited epithelial proliferation in fully mature uterine epithelium even in the absence of ER $\alpha$ in the stroma (Bigsby et al., 2004; Cooke et al., 1997).

\section{Mammary ductal growth in the mouse is mediated via ERainthest roma}

Mammary glands of adult $\alpha$ ERKO mice are rudimentary, and alveoli do not form even though embryonic development of the mammary gland is normal (Bocchinfuso and Korach, 1997). The lack of ductal outgrowth at puberty in $\alpha$ ERKO mice could result from an absence of ER $\alpha$ signaling either in the stroma (fat pad), epithelium, or both. To resolve the respective roles of epithelial versus stromal $\mathrm{ER} \alpha$ in mammary ductal growth, the four possible tissue recombinants were constructed with an epithelium (E) and fat pad (FP) from neonatal wt and ERd knock-out (KO) mice: wt-FP+wt-E, wt-FP+ $\alpha$ ERKO-E, $\alpha$ ERKO-FP $+\alpha$ ERKO-E, and $\alpha$ ERKO-FP+wt-E (Cunha et al., 1997). Tissue recombinants were grown as subrenal capsule grafts in nude mice. Impaired ductal growth was observed when an $\alpha$ ERKO fat pad was used ( $\alpha$ ERKO-FP $+\alpha$ ERKO-E

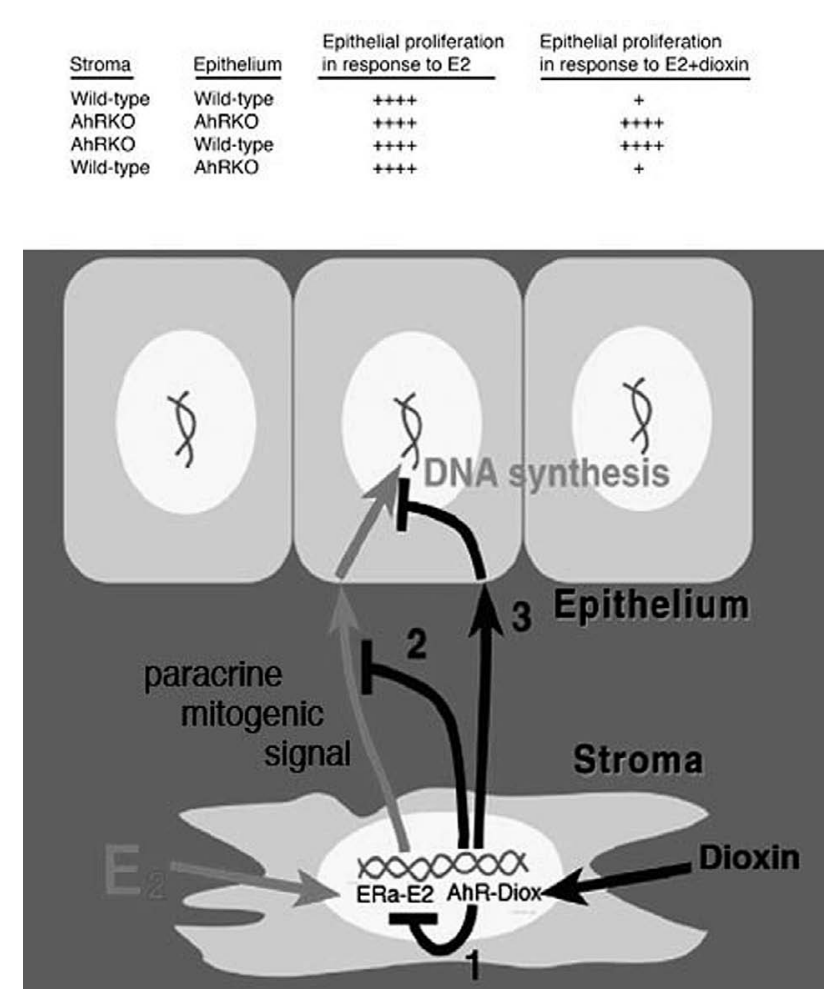

Fig. 6. Dioxin inhibition of estrogen-induced uterine epithelial proliferation. Uterine tissue recombinants were prepared with wild-type (AhR-positive) and AhRKO (AhR-negative) epithelium and stroma. As indicated above (Fig. 3) estradiol stimulates uterine epithelial proliferation via paracrine influences. Estrogen-induced uterine epithelial proliferation is inhibited by dioxin mediated via AhR in the stroma (see figure). There are several mechanistic scenarios: 1) Dioxin may act within the stroma cell to prevent elaboration of the estrogen-induced trophic factor, 2) Dioxin may induce the synthesis and secretion of a factor that can neutralize the estrogen-induced trophic factor in the extracellular compartment, 3) Dioxin may induce the synthesis and secretion of a paracrine factor (such as $\operatorname{TGF} \beta$ ) that upon reception by the epithelial cell inhibits uterine epithelial proliferation.

and $\alpha$ ERKO-FP+wt-E) (Fig. 4). Extensive ductal growth occurred when a wt fat pad was used (wt-FP+wt-E and wt$\mathrm{FP}+\alpha \mathrm{ERKO}-\mathrm{E}$ ). These studies demonstrated that the estrogenic stimulation of ductal growth is a paracrine event mediated by ER $\alpha$-positive stromal cells. In adulthood it appears that the $\operatorname{ER} \alpha$ requirement for ductal growth is slightly different. In these experiments, mammary epithelial cells were isolated from adult $\alpha$ ERKO mice and wt mice and were injected into syngeneic epithelial-free mammary 
fat pads of 3-wk-old female $\alpha$ ERKO or wt mice. These studies revealed that both stromal and epithelial ER $\alpha$ are required for maximum mammary ductal growth (Mueller et al., 2002), similar to that in the uterine study described above (Bigsby et al., 2004). Presumably, ER $\alpha$-mediated ductal morphogenesis and alveolar development may involve the induction of estrogen-responsive genes (such as $\mathrm{PR}$ ) within the mammary gland and perhaps also in peripheral endocrine tissues that contribute to mammary gland development and function. Incidentally, mammary ductal growth is normal in $\mathrm{ER} \beta$ knockout $(\beta \mathrm{ERKO})$ mice (Krege et al., 1998).

\section{Stromal progesterone receptors mediate the inhibitory effects of progesterone on estrogen- induced uterine epithelial proliferation}

Uterine epithelial proliferation is regulated by estradiol and progesterone, whose levels fluctuate through estrous and menstrual cycles. Estradiol induces uterine epithelial proliferation, while progesterone promotes functional differentiation and inhibits epithelial proliferation. In rodents, Martin et al demonstrated that pretreatment with progesterone inhibits estrogen-induced uterine epithelial proliferation (Martin et al., 1973). Progesterone elicits its effects through the $\mathrm{PR}$, which is expressed in epithelial, stromal and myometrial cells of the uterus (Ohta et al., 1993). While it is logical that progesterone would inhibit uterine epithelial proliferation by acting through epithelial PR, the presence of stromal PR raises the possibility that progesterone may inhibit estrogen-induced uterine epithelial proliferation through it. Tissue recombinants composed of uterine tissues from PRKO and wt mice were used to resolve this issue (Kurita et al., 1998). In this way, we produced the following tissue recombinants in which $\mathrm{PR}$ was present or absent in epithelium, stroma, or both: wt-S+wt-E, PRKO-S+PRKO-E, wtS+PRKO-E, and PRKO-S+wt-E. Tissue recombinants were grown as grafts in female nude mice for 4 weeks, and then all hosts were ovariectomized. Two weeks following ovariectomy, hosts received estradiol with or without progesterone. Eighteen hours after the last hormone injection, epithelial labeling index was determined using ${ }^{3} \mathrm{H}$-thymidine autoradiography. In response to estradiol, all four types of tissue recombinants (wt-S+wt-E, PRKO-S+PRKOE, wt-S+PRKO-E, and PRKO-S+wt-E) showed a severalfold increase in the epithelial labeling index compared with the oil-treated group (Fig. 5). In tissue recombinants prepared with PR-positive wt stroma (wt-S+wt-E, wtS+PRKO-E), estradiol-induced epithelial proliferation was profoundly inhibited by progesterone, even in the wt-
S+PRKO-E tissue recombinants, which lacked epithelial PR. This indicated a key role for stromal PR in the inhibition of uterine epithelial proliferation (Fig. 5). Conversely, in tissue recombinants prepared with PRKO stroma (PRKO-S+PRKO-E and PRKO-S+wt-E), progesterone did not inhibit estrogen-induced epithelial proliferation. Thus, epithelial proliferation remained elevated to levels comparable to those of estradiol-treated tissue recombinants even in PRKO-S+wt-E grafts, which contained epithelial PR. These results demonstrate that stromal PR is both essential and sufficient to mediate the inhibitory effect of progesterone on estrogen-induced uterine epithelial proliferation (Kurita et al., 1998). Moreover, epithelial PR is neither necessary nor sufficient for the progesterone inhibition of estrogen-induced epithelial proliferation in the mouse uterine epithelium.

\section{Stromal aryl hydrocarbon receptors mediate the inhibitory effects of dioxin on estrogen- induced uterine epithelial proliferation}

The prototypical AhR ligand, 2,3,7,8-tetrachlorodibenzo- $p$ dioxin (TCDD), is the most environmentally ubiquitous dioxin, and a variety of studies have indicated that TCDD can have potent anti-estrogenic effects on the rodent uterus in vivo and on the proliferation of MCF-7 cells in vitro (Gallo et al., 1986; Gierthy et al., 1993; Holcomb and Safe, 1994). Since E2 induction of uterine epithelial proliferation is induced through stromal ER $\alpha$ (Cooke et al., 1997), we determined whether TCDD could inhibit processes such as estradiol-induced uterine epithelial proliferation through AhR in the epithelium and/or stroma.

To determine through which tissue compartment(s) TCDD acted to inhibit the E2-induced uterine epithelial proliferation, we employed a tissue separation-recombination methodology using uterine tissues from wt and AhRKO mice. Our initial results indicated that both uterine epithelium and stroma expressed AhR (Buchanan et al., 2000). Tissue recombinants consisting of a wild-type uterine stroma and wild-type (wt-S+wt-E) uterine epithelium showed a marked decrease in epithelial proliferation in response to estradiol plus TCDD compared with similar tissue recombinants grown in hosts receiving estradiol alone (Fig. 6). This inhibitory response was not seen in AhRKO$\mathrm{S}+\mathrm{AhRKO}-\mathrm{E}$ tissue recombinants. Likewise, the anti-estrogenic effects of TCDD were not seen in tissue recombinants composed of an AhRKO uterine stroma plus a wt uterine epithelium, suggesting that the anti-estrogenic effects of TCDD were mediated through a stromal AhR. This was confirmed when uterine stroma from AhRKO mice was recombined with wt uterine epithelium in which 


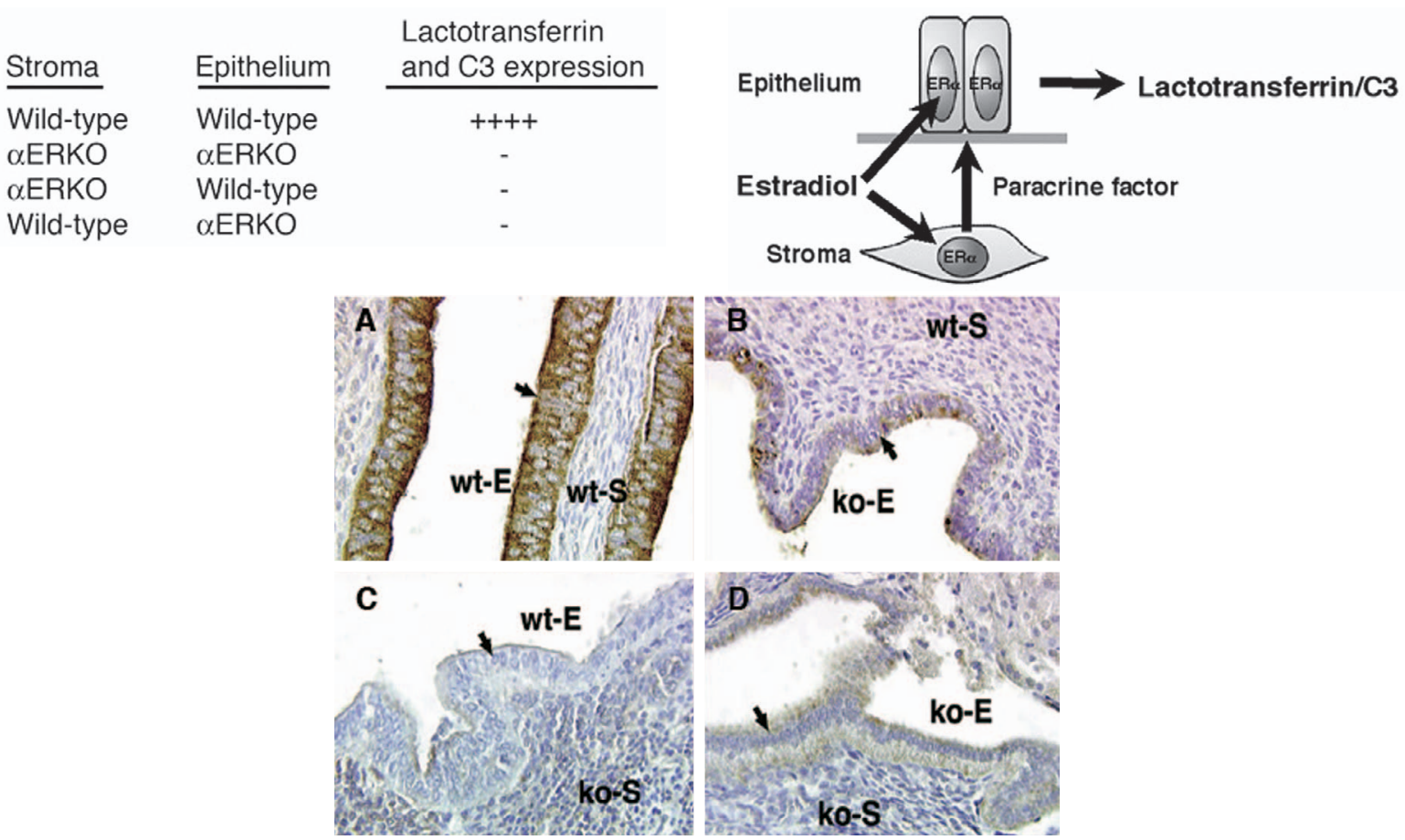

Fig. 7. Estrogen-induced expression of uterine epithelial secretory proteins, lactotransferrin and C3, in uterine tissue recombinants prepared wild-type (ER $\alpha$-positive) and $\alpha \mathrm{ERKO}$ (ER $\alpha$-negative) epithelium and stroma. as indicated in the table(upper left). The immunohistochemical images, stained for lactotransferrin, are tissue recombinants composed of A) wild-type stroma (wtS) + wild-type epithelium (wtE), B) wild-type stroma (wtS) $+a$ ERKO epithelium (koE), C) $a$ ERKO stroma (koS) + wild-type epithelium (wtE), and D) $a$ ERKO stroma $(\mathrm{koS})+a$ ERKO epithelium (koE). Expression of lactotransferrin is undetectable in all 4 types of tissue recombinants grown in ovariectomized hosts (not shown). Estradiol stimulated a dramatic up-regulation of lactotransferrin (A) and C3 only in the tissue recombinants prepared with a wildtype (ER $\alpha$-positive) stroma plus wild-type (ER $\alpha$-positive) epithelium. This indicates that estrogen induction of uterine epithelial secretory proteins requires both epithelial and stromal $\alpha \mathrm{ER}$ and thus both direct and paracrine effects (see cartoon).

TCDD failed to inhibit estradiol-induced uterine epithelial proliferation (Buchanan et al., 2000). Thus, TCDD acts through a stromal AhR to inhibit estradiol-stimulated uterine epithelial proliferation, while no epithelial AhR is involved. A possible explanation for these results is that the liganded AhR may alter the normal stromal response to ER $\alpha$ activation in this tissue to diminish the production of the putative stromal signal that induces epithelial proliferation in response to estradiol.

\section{Regulation of epithelial differentiation in the female reproduction tract}

Estradiol is a regulator of uterine epithelial secretory proteins such as lactoferrin (Pentecost et al., 1988) and complement component C3 (Sundstrom et al., 1989). The inability of $\alpha \mathrm{ERKO}$ mice lacking $\mathrm{ER} \alpha$ to induce lactoferrin in response to estradiol treatment indicates that $\mathrm{ER} \alpha$ is essential for this process (Couse et al., 1995). The relative role of epithelial versus stromal $\operatorname{ER} a$ s in the induction of 
uterine secretory proteins and their mRNAs was examined using the same four types of uterine tissue recombinants used in our earlier studies of estradiol-induced epithelial proliferation: wt-S+wt-E, wt-S+ $\alpha$ ERKO-E, $\alpha$ ERKO-S+ $a$ ERKO-E, $\alpha$ ERKO-S+wt-E (Buchanan et al., 1998b). These were grown in intact female nude mice, which were subsequently ovariectomized and injected daily with oil or estradiol for up to 3 days. Grafts were recovered, and lactoferrin and $\mathrm{C} 3$ were assessed at the protein and mRNA levels. The results demonstrated that lactoferrin protein or mRNA induction by estradiol required both stromal and epithelial ER $\alpha$ (wt S wt E)(Fig. 7). The absence of ER $\alpha$ in either tissue compartment abolished the induction of lactoferrin or its mRNA. Similar results were obtained with C3, demonstrating the dependence of estradiol-induced secretory protein production on the simultaneous presence of both the stromal and epithelial $\operatorname{ER} a$. This dependence on both stromal and epithelial ER $\alpha$ contrasts dramatically with estradiol-induced epithelial mitogenesis, which requires only stromal ER $a$. The obligatory role for epithelial ER $\alpha$ in mediating the normal estradiol-induced production of uterine epithelial secretory products is the first known function attributed to epithelial ER $\alpha$ in vivo. Furthermore, the demonstration that both stromal and epithelial ER $\alpha$ are necessary for the production of uterine epithelial secretory proteins represents the first time any epithelial response to estradiol has been shown to simultaneously require ER $\alpha$ in both the stromal and epithelial compartments.

Comparable results were obtained for vaginal epithelium, which responds to estradiol by undergoing cornification, a response that involves both proliferative and differentiative events. Through analysis of the same four types of vaginal tissue recombinants used earlier, we concluded that the full manifestation of vaginal cornification involves epithelial proliferation, which is mediated via stromal ER $a$ and expression of proteins associated with cornification (keratin 10, involucrin, etc.) whose expression is mediated via the epithelial ER $\alpha$ (Fig. 8) (Buchanan et al., 1998a; Kurita et al., 2001a). Thus, the emerging pattern is that epithelial proliferation is mediated via stromal receptors, and the functional differentiation of the epithelium simultaneously requires epithelial receptors.

Another differentiation marker of uterine and vaginal epithelia is the PR, which is one of the most well studied estrogen-regulated genes. In most cells/tissues, PR is upregulated by estrogen. Accordingly, in vaginal epithelial cells in vivo, PR is undetectable in ovariectomized mice and strongly expressed following estrogen treatment (Kurita et al., 2000a). In contrast, mouse uterine epithelium expresses high levels of PR in the absence of estrogen, and, surprisingly, estrogen down-regulates PR in mouse uterine epithelium (Murakami et al., 1990; Tibbetts et al., 1998).
This unusual expression pattern of PR is unique for uterine epithelium of rats and mice. Predictably, PR is highly expressed in uterine epithelium of $a$ ERKO mice and is not down-regulated by estrogen (Kurita et al., 2000a). In vaginal epithelium of $\alpha$ ERKO mice PR is low or undetectable with or without estrogen treatment. Thus, regulation of PR via $\operatorname{ER} \alpha$ signaling is completely opposite between uterine and vaginal epithelia in the mouse. Estrogen up-regulates PR in vaginal epithelium and down-regulates PR in uterine epithelium. It is puzzling how $\operatorname{ER} \alpha$ can have opposite effects (activation and suppression) on PR in the uterus and vagina. We have demonstrated fundamental differences in the cellular mode of estrogen regulation of epithelial PR in the uterus and vagina through analysis of tissue recombinants composed of vaginal and uterine epithelia $(E)$ and stroma (S) from wt and $\alpha$ ERKO mice: wt-S+wt-E, wt-S+ $a$ ERKO-E, $\alpha$ ERKO-S $+\alpha$ ERKO-E, $\alpha$ ERKO-S+wt-E. These tissue recombinants were grown for 4 weeks under the renal capsule of female hosts, which were then ovariectomized. PR was undetectable or very low in both vaginal epithelium and stroma in all 4 types of vaginal tissue recombinants in ovariectomized hosts treated with oil only. PR was strongly expressed in both the epithelium and stroma of wt-S+wt-S vaginal tissue recombinants treated with estradiol but was undetectable in $a$ ERKO-S $+\alpha$ ERKO-E vaginal tissue recombinants (Fig. 9) (Kurita et al., 2000a). In wt-S $+\alpha$ ERKO-E and $\alpha$ ERKO-S+wt-E tissue recombinants, E2-treatment respectively induced PR only in the wt$\mathrm{S}$ or wt-E, respectively. Therefore, PR expression is directly regulated by estrogen in vivo in vaginal stroma and epithelium through ERs in the responding tissue.

In contrast to the vagina, all four types of uterine tissue recombinants (wt-S+wt-E, wt-S $+\alpha$ ERKO-E, $\alpha$ ERKO-S+ $a$ ERKO-E, $\alpha$ ERKO-S+wt-E) strongly express PR in epithelia of the oil-treated group. Epithelial PR was downregulated by $\mathrm{E} 2$ in uterine tissue recombinants prepared with wt-S (wt-S+wt-E and wt-S+ + ERKO-E). Even in the absence of functional epithelial $\operatorname{ER} \alpha$ in uterine wt-S+ $a$ ERKO-E tissue recombinants, estradiol dramatically reduced the PR level in the epithelium (Fig. 10). Conversely, estradiol did not down-regulate epithelial PR in uterine tissue recombinants prepared with $\alpha$ ERKO-S ( $\alpha$ ERKO$\mathrm{S}+\mathrm{wt}-\mathrm{E}$ and $\alpha \mathrm{ERKO}-\mathrm{S}+\alpha \mathrm{ERKO}-\mathrm{E}$ ) despite the expression of epithelial ER $\alpha$ in the $\alpha$ ERKO-S+wt-E tissue recombinants. These results definitively demonstrate that $\operatorname{ER} \alpha$ in uterine stroma are essential for the down-regulation of uterine epithelial PR induced by estradiol treatment. ER $\alpha$ in uterine epithelium are neither necessary nor sufficient for an estrogen-induced down-regulation of uterine epithelial PR. Thus, uterine epithelial PR expression is regulated by estradiol through a paracrine mechanism, which is mediated via stromal ERas (Kurita et al., 2000a). 


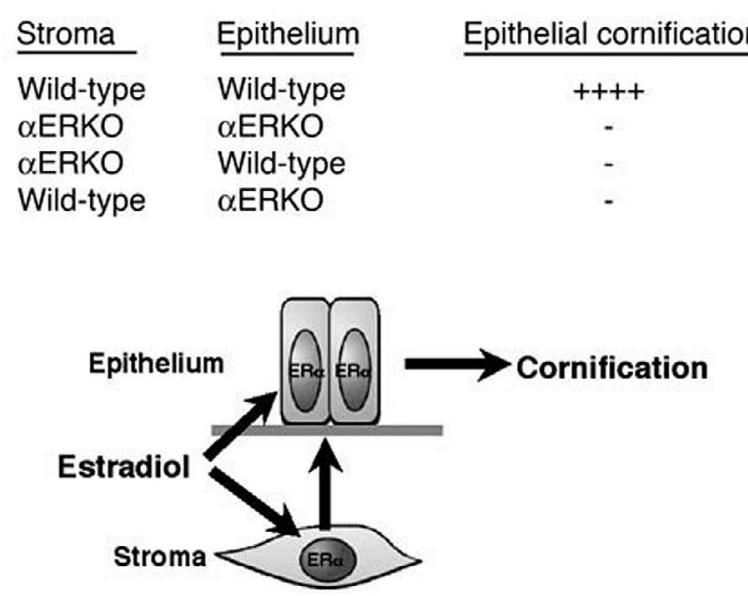

Fig. 8. Estrogen-induced vaginal epithelial cornification. Vaginal tissue recombinants were prepared with wild-type (ER $\alpha$ positive) and $\alpha$ ERKO (ER $\alpha$-negative) epithelium and stroma. Estradiol induced vaginal epithelial cornification only in the tissue recombinants prepared with a wild-type (ER $\alpha$-positive) stroma plus a wild-type (ER $\alpha$-positive) epithelium. This indicates that the estrogen induction of vaginal epithelial cornification requires both epithelial and stromal ER $\alpha$ and thus both direct and paracrine effects. The paracrine effect required for vaginal epithelial cornification is proliferation (see Fig. 3). Epithelial cornification was assessed by histology as well as through the expression of a variety of differentiation markers associated with vaginal epithelial cornification (keratins, involucrin, etc.).

This differential pattern of regulation by PR in uterine and vaginal epithelia is the result of uterine and vaginal stromal induction during development (Kurita et al., 2001a). Both the uterus and the upper vagina (Müllerian vagina) develop from the Müllerian duct. Tissue recombination experiments have shown that neonatal uterine and vaginal epithelia can be induced by the stroma to change their differentiation pattern during the first week after birth (Cunha, 1976; Kurita et al., 2001a). We have recently determined that the p63 transcription factor is the identity switch for uterine and vaginal epithelial differentiation (Kurita and Cunha, 2001; Kurita et al., 2004). When p63 is induced by a vaginal stroma $(\mathrm{VgS})$ in uterine Müllerian duct epithelial (UtE) cells, vaginal differentiation occurs (Table 1). When vaginal Mullerian duct epithelial cells $(\mathrm{VgE})$ are grown in association with a uterine stroma (UtS, $\mathrm{UtS}+\mathrm{VgE}$ recombinants), p63 is not induced and uterine differentiation occurs. Accordingly, the Mullerian vagina of

\begin{tabular}{|c|c|c|c|}
\hline Stroma & Epithelium & Stromal PR & Epithelial PR \\
\hline Wild-type & Wild-type & ++++ & ++++ \\
\hline$\alpha$ ERKO & $\alpha$ ERKO & - & - \\
\hline$\alpha$ ERKO & Wild-type & - & ++++ \\
\hline Wild-type & $\alpha$ ERKO & ++++ & - \\
\hline
\end{tabular}

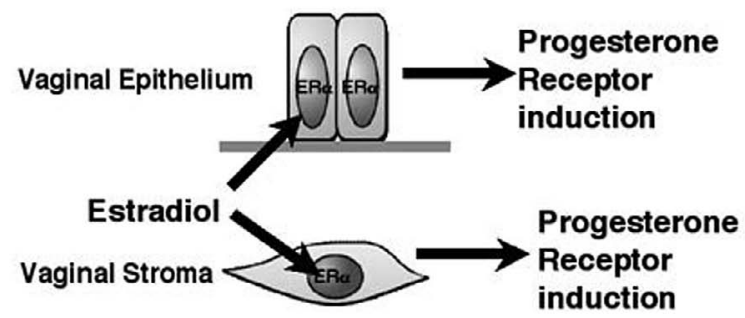

Fig. 9. Regulation of vaginal progesterone receptors by estradiol. Vaginal tissue recombinants were prepared with wild-type (ER $\alpha$-positive) and $\alpha$ ERKO (ER $\alpha$-negative) epithelium and stroma. Estradiol induces vaginal epithelial and stromal progesterone receptors by direct action. If $\mathrm{ER} \alpha$ is present in either epithelial or stromal cells, estradiol induces progesterone receptors in the target cell irrespective of the status of the interacting partner tissue.

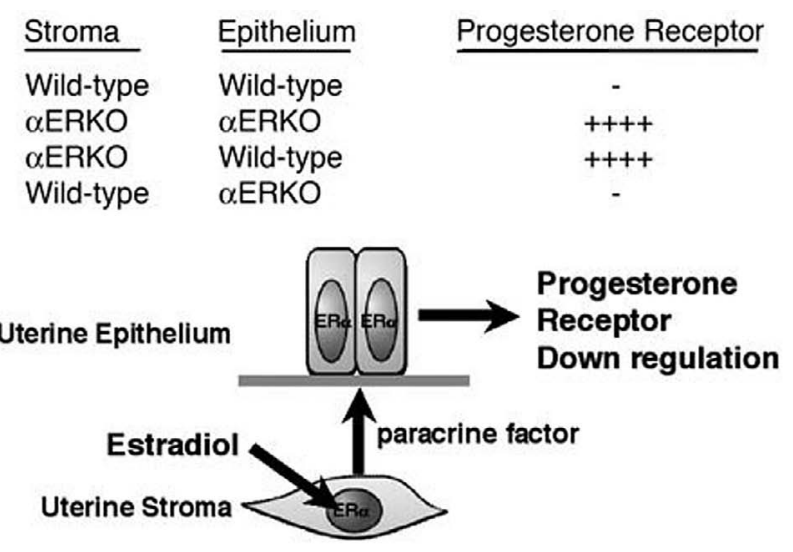

Fig. 10. Regulation of uterine epithelial progesterone receptors by estradiol. As indicated in the text of this review, estradiol down regulates uterine epithelial PR in mice and rats. To study the cell-cell interactions involved in down regulating uterine epithelial PR, tissue recombinants were prepared with wild-type (ER $\alpha$-positive) and $\alpha$ ERKO (ER $\alpha$-negative) uterine epithelium and stroma. In response to estradiol, uterine epithelial PR down regulated only in tissue recombinants composed of a wild-type stroma plus a wild-type epithelium or a wild-type stroma plus an $a$ ERKO epithelium, indicating that the down regulation of uterine epithelial PR is mediated via paracrine influences from an $\mathrm{ER} a$-positive uterine stroma. 
Table 1. Uterine and vaginal epithelial features are induced and determined by the mesenchyme with which the epithelium is associated during development.

\begin{tabular}{|c|c|c|c|c|c|c|c|}
\hline \multirow[b]{3}{*}{ Stroma } & \multirow[b]{3}{*}{ Epithelium } & \multicolumn{6}{|c|}{ Epithelial features } \\
\hline & & \multirow{2}{*}{ Differentiation } & \multirow{2}{*}{ p63 } & \multirow{2}{*}{ Keratin14 } & \multirow{2}{*}{$\begin{array}{c}\text { Involucrin } \\
\left(E_{2}\right)\end{array}$} & \multicolumn{2}{|c|}{ PR } \\
\hline & & & & & & oil & E2 \\
\hline uterus & uterus & uterus & - & - & - & + & - \\
\hline vagina & vagina & vagina & + & + & + & - & + \\
\hline uterus & vagina & uterus & - & - & - & + & - \\
\hline vagina & uterus & vagina & + & + & + & - & + \\
\hline
\end{tabular}

From Cunha (1976); Kurita et al. (2001a, 2004)

p63 knockout mice differentiates into uterine epithelium and expresses a high level of PR in the absence of E2 (uterine pattern of PR regulation) (Kurita et al., 2004).

In the uterine epithelium, progesterone antagonizes estradiol-induced gene expression. Both the induction of lactoferrin and repression of PR by estradiol are inhibited by progesterone in the uterine epithelium. Tissue recombination studies using uterine tissues from PRKO and wt mice have confirmed the involvement of stromal PR in the antagonism by progesterone of estradiol induction of PR and lactoferrin in uterine epithelia. Progesterone regulation of epithelial PR was studied in wt-S+wt-E and PRKO-S+wt-E tissue recombinants (Fig. 11). Estradiol down-regulated epithelial PR in both types of tissue recombinants, but epithelial PR remained elevated following estradiol plus progesterone treatment only in wt-S+wt-E tissue recombinants. PR was not regulated by progesterone in PRKOS+wt-E tissue recombinants even though PR was expressed in the epithelium. Thus, progesterone requires stromal PR to inhibit estradiol-induced down-regulation of epithelial PR (Kurita et al., 2000b). Epithelial PR is not sufficient in itself.

The inhibitory effect of progesterone on uterine lactoferrin expression was also studied in the four types of uterine tissue recombinants (wt-S+wt-E, PRKO-S+wt-E, wt-S + PRKO-E and PRKO-S+PRKO-E). Estradiol induced lactoferrin in all four types of uterine tissue recombinants irrespective of the PR status of the epithelium and stroma, presumably by estradiol action via ER $\alpha$ present in both the epithelium and stroma. Progesterone blocked estradiolinduced lactoferrin expression only in wt-S+wt-E tissue recombinants in which PR was present in both the stroma and epithelium (Fig. 12). Progesterone failed to block E2induced lactoferrin expression in wt-S+PRKO-E, PRKOS+wt-E and PRKO-S+PRKO-E tissue recombinants. Thus, both epithelial and stromal PR are essential for the full antagonism of progesterone on an E2-induced lactoferrin expression (Kurita et al., 2000b).

\section{Induction of prostatic squamous metaplasia requires both stromal and epithelial ER $\alpha$}

Estrogenic effects on the prostate are complex and involve both direct and indirect actions. Squamous metaplasia is a direct effect of estrogen on the prostate induced by longterm exposure to high levels of exogenous or endogenous estrogen (Risbridger et al., 2001a). Prostatic squamous metaplasia is usually reversible following removal of the estrogenic stimulus. Squamous metaplasia of the prostatic epithelium is characterized by the total replacement of the columnar secretory epithelium by layers of stratified squamous cells (Risbridger et al., 2001a). Estrogenic induction of prostatic squamous metaplasia is mediated through $\operatorname{ER} \alpha$ signaling. The prostate has two estrogen receptor subtypes, $\mathrm{ER} \alpha$ and $\operatorname{ER} \beta$ (Lubahn et al., 1993; Kuiper et al., 1996). $\mathrm{ER} \alpha$ and $\operatorname{ER} \beta$ are predominantly expressed in the prostatic stroma and epithelium, respectively (Lau et al., 1998; Prins et al., 1998; Chang and Prins, 1999). The roles of ER $\alpha$ and $\mathrm{ER} \beta$ in prostatic squamous metaplasia have been studied through use of $\alpha$ ERKO and $\beta$ ERKO mice (Risbridger $e t$ $a l ., 2001$ a). In our studies, DES induced prostatic squamous metaplasia in wt and $\beta$ ERKO mice, but not in $\alpha$ ERKO mice (Risbridger et al., 2001b). Thus, signaling through an ER $\alpha$ is required for the induction of prostatic squamous metaplasia. The respective role of epithelial versus stromal ER $\alpha$ in the induction of prostatic squamous metaplasia was examined by analyzing prostatic tissue recombinants constructed with a prostatic stroma (S) and epithelium (E) from wt or $a$ ERKO mice: wt-S+wt-E, $\alpha$ ERKO-S $+\alpha$ ERKO-E, wt-S $+\alpha$ ERKO-E, and $\alpha$ ERKOS+wt-E. All tissue recombinants were grown under the renal capsules of intact male nude mice for four weeks to allow prostatic development to proceed. The hosts were 

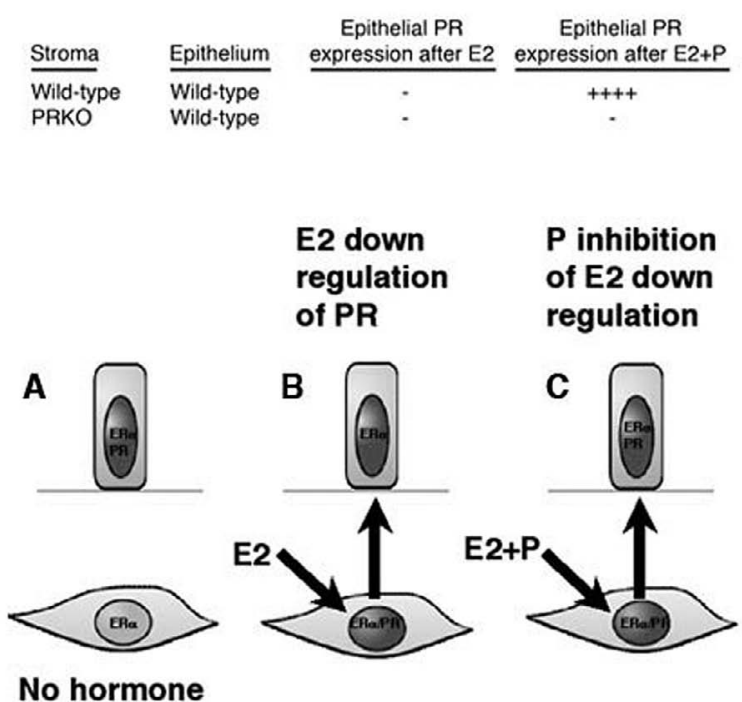

Fig. 11. Regulation of uterine epithelial progesterone receptors by progesterone. As indicated above (Fig. 10) estradiol down regulates uterine epithelial PR via paracrine influences from an $\mathrm{ER} a$-positive uterine stroma. Thus, in the absence of hormone (A) uterine epithelium expresses PR as well as ER $\alpha$. In response to estradiol, uterine epithelial PRs are down regulated, a process requiring an $\mathrm{ER} \alpha$-positive uterine stroma and thus mediated via paracrine influences (B). To study the cell-cell interactions involved in the effect of progesterone in combination with estradiol on the uterine epithelial PR, tissue recombinants were prepared with wild-type (PR-positive) and PRKO (PR $\alpha$-negative) uterine epithelium and stroma. In response to estradiol, uterine epithelial PR is down regulated via paracrine influences from the ER $\alpha$-positive uterine stroma. This down regulation of uterine epithelial PR is inhibited by progesterone acting via stromal PR (C), and thus PR is elevated.

then treated with subcutaneous pellets containing the synthetic estrogen, diethylstilbestrol (DES), for three weeks. Squamous metaplasia was only observed in wt-S+wt-E tissue recombinants and not in $\alpha$ ERKO-S $+\alpha$ ERKO-E, wt-S+ $\alpha$ ERKO-E, $\alpha$ ERKO-S+wt-E tissue recombinants (Fig. 13). These results revealed the importance of stromal-epithelial interactions and a requirement of both epithelial and stromal $\operatorname{ER} a$ to elicit estrogen-induced prostatic squamous metaplasia. It should be noted that prostatic squamous metaplasia is similar in many ways to vaginal cornification. Both conditions involve epithelial proliferation as well as epithelial keratinization. Presumably, the development of prostatic squamous metaplasia involves the stimulation of epithelial proliferation mediated by stromal $\operatorname{ER} \alpha$ and an

\begin{tabular}{|c|c|c|c|}
\hline Stroma & Epithelium & $\begin{array}{l}\text { Lactotransferrin } \\
\text { expression after E2 }\end{array}$ & $\begin{array}{c}\text { Lactotransferrin } \\
\text { expression after } \mathrm{E} 2+\mathrm{P}\end{array}$ \\
\hline Wild-type & Wild-type & ++++ & +1 \\
\hline PRKO & PRKO & ++++ & ++++ \\
\hline PRKO & Wild-type & ++++ & ++++ \\
\hline Wild-type & PRKO & ++++ & ++++ \\
\hline
\end{tabular}

$$
\begin{aligned}
& \text { E2 induction } \\
& \text { of lactotransferrin }
\end{aligned}
$$

\section{P inhibition of E2- induced lactotransferrin}
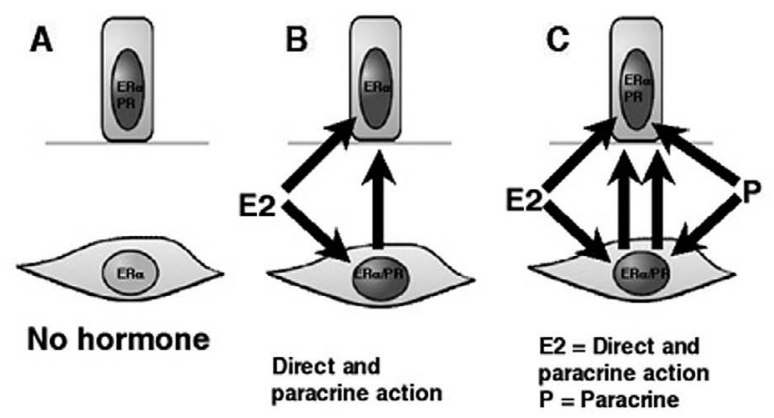

Fig. 12. Down regulation of uterine epithelial secretory proteins by progesterone. As indicated above (Fig. 7), estradiol induces lactotransferrin in the uterine epithelium via both epithelial and stromal ER $a$ and thus requires both direct and paracrine effects. Thus, in the absence of hormone (A) lactotransferrin is not expressed in uterine epithelium. In response to estradiol lactotransferrin is induced, and the process requires both the epithelial and stromal $\operatorname{ER} \alpha(\mathbf{B})$, that is, both direct and paracrine mechanisms are involved. Progesterone given in combination with estradiol inhibits lactotransferrin expression but only in tissue recombinants composed of wild-type (PR-positive) stroma and epithelia, thus suggesting that the inhibitory effect of progesterone on lactotransferrin expression is also mediated by both direct and paracrine mechanisms $(\mathbf{C})$.

epithelial squamous differentiation mediated by epithelial ER $a$ s.

\section{Stromal-epithelial interactions in the induction of cervicovaginal adenosis}

While estrogens are important physiologic signaling molecules in the female genital tract, exogenous estrogens administered during development can have both teratogenic and carcinogenic consequences in animals and humans. For example, DES was prescribed for pregnant women to prevent miscarriage, and women exposed to DES in utero (DES daughters) exhibit genital tract abnormalities includ- 


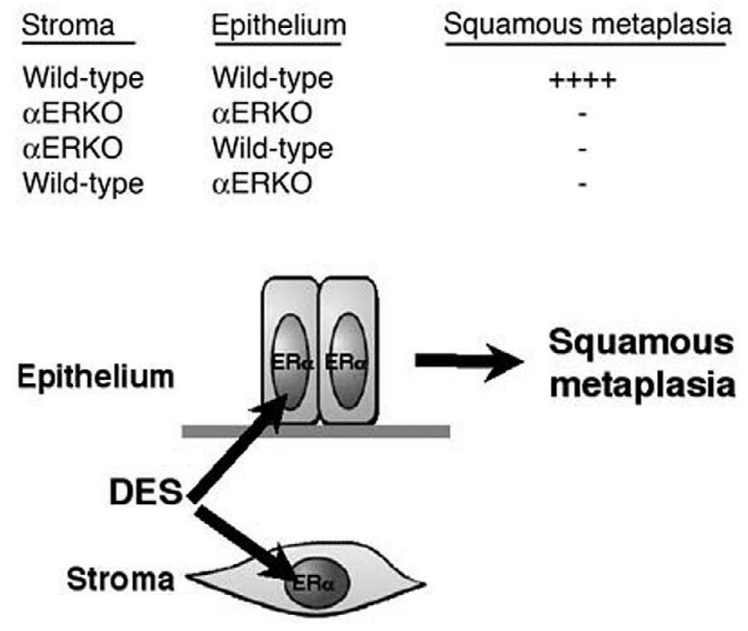

Fig. 13. Estrogen-induced squamous metaplasia of a prostatic epithelium. Prostatic tissue recombinants were prepared wildtype (ER $\alpha$-positive) and $\alpha$ ERKO (ER $\alpha$-negative) epithelium and stroma. Diethylstilbestrol (DES) induced squamous metaplasia only in prostatic tissue recombinants prepared with wildtype (ER $\alpha$-positive) stroma plus wild-type (ER $\alpha$-positive) epithelium. This indicates that the estrogen induction of prostatic squamous metaplasia requires both epithelial and stromal $a$ ERs and thus both direct and paracrine effects.

ing cervicovaginal adenosis, which is characterized by the presence of columnar epithelia in the cervix and/or vagina (Robboy et al., 1981). DES daughters are at risk to develop clear-cell adenocarcinoma of the vagina (Herbst et al., 1971), and adenosis is thought to be its precursor (Robboy et al., 1981). Perinatal exposure of mice to DES induces a spectrum of reproductive tract lesions similar to those observed in humans (Forsberg, 1976; McLachlan et al., 1980; Plapinger and Bern, 1979). The mechanism of DESinduced cervicovaginal adenosis is not well understood, except for the fact that ER $\alpha$ is essential for the development of cervicovaginal adenosis induced by neonatal DESexposure (Couse et al., 2001).

p63 is an identity switch for the differentiation of Müllerian duct epithelium into the squamous vaginal epithelium (Kurita et al., 2004). p63 is a homologue of the p53 tumor suppressor gene (Yang et al., 1998). During the course of differentiation, p63 is initially undetectable in the embryonic Müllerian duct. The middle portion of the Mullerian duct, destined to become the uterine epithelium, remains p63-negative. The lower portion of the Müllerian

\begin{tabular}{|c|c|c|}
\hline Stroma & Epithelium & Adenosis \\
\hline Wild-type & Wild-type & + \\
\hline$\alpha$ ERKO & $\alpha$ ERKO & \\
\hline$\alpha$ ERKO & Wild-type & + \\
\hline Wild-type & $\alpha$ ERKO & - \\
\hline
\end{tabular}
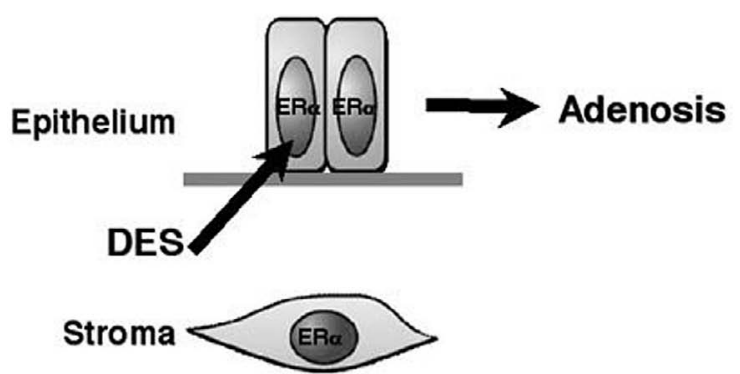

Fig. 14. DES-induced adenosis of a vaginal epithelium. Tissue recombinants were prepared with wild-type (ER $\alpha$-positive) and $\alpha$ ERKO (ER $\alpha$-negative) uterine epithelia and vaginal stromas. Diethylstilbestrol (DES) induced adenosis only in tissue recombinants prepared with a wild-type (ER $\alpha$-positive) epithelium. Thus, induction of vaginal adenosis appears to be a direct effect of DES on the epithelium mediated by epithelial $\operatorname{ER} \alpha$.

duct, destined to become the stratified squamous cervicovaginal epithelium, expresses p63 from about 18 days of gestation and thereafter. In mice treated neonatally with DES, the normal expression of a continuous layer of p63positive basal epithelial cells was greatly inhibited in the Müllerian vagina and the cervix. This was manifested at day 5 as large gaps in the p63-positive basal epithelial layer in the fornix and common cervical canal, the primary site for the development of cervicovaginal adenosis (Forsberg and Kalland, 1981). A few days after the last DES injection on day 5 , most of the gaps in the p63-positive layer in the cervicovaginal epithelium were filled-in with p63-positive cells, but small patches of p63-negative epithelial cells remained in the fornix and common cervical canal as adenotic lesions. Thus, DES impaired the normal ontogeny of p63 in the developing cervicovaginal epithelium leading to foci of p63 negative glandular tissue in the cervix and vagina, adenosis (Kurita et al., 2004).

DES induces vaginal adenosis via $\mathrm{ER} a$. Thus, DES disruption of p63 expression was never seen in the cervicovaginal epithelium of $\alpha$ ERKO mice, i.e., the p63-positive 
basal epithelial layer developed normally in DEStreated $\alpha$ ERKO mice. DES action on p63 in the developing cervicovaginal epithelium therefore requires $\operatorname{ER} \alpha$. In the neonatal cervix and Mullerian vagina, $\mathrm{ER} a$ is highly expressed in both epithelial and mesenchymal cells (Kurita et al., 2001a). Consequently, DES action may be elicited via signaling through ER $a$ in either epithelial and/or mesenchymal cells. To determine whether DES disrupts the induction of p63 and thus induces adenosis via ER $a$ in epithelial or mesenchymal cells, the four types of tissue recombinants were constructed with a uterine epithelium (UtE) and vaginal mesenchyme (VgM) from $\alpha$ ERKO and wt mice (wt-VgM+ wt-UtE, wt-VgM+ $+\alpha$ ERKO-UtE, $\alpha$ ERKO-VgM+wt-UtE and $\alpha$ ERKO-VgM+ $+\alpha$ ERKO-UtE) and grafted into ovariectomized female nude mice. In untreated hosts, the vaginal mesenchyme induced a p63positive squamous basal epithelial layer in an originally p63-negative uterine epithelium in all four types of tissue recombinants (Fig. 14), which is indicative of normal cervicovaginal epithelial differentiation. When hosts were treated with DES, squamous p63-positive basal cells were not detected in the tissue recombinants prepared with a wt-uterine epithelium (wt-VgM+wt-UtE and $\alpha$ ERKO-VgM+wtUtE), indicating that DES had inhibited normal cervicovaginal differentiation by direct action on epithelial ER $a$. In contrast, when an $\alpha$ ERKO uterine epithelium was used to construct the tissue recombinants (wt-VgM+ $\alpha$ ERKO$\mathrm{UtE}$ and $\alpha$ ERKO-VgM+ $+\alpha$ ERKO-UtE), a normal p63-positive squamous basal epithelial layer developed even when the hosts were treated with DES. These results demonstrate that DES acts via the epithelial ER $a$ to the inhibit induction of p63 and thus to induce adenosis in cervicovaginal epithelium. DES action via the mesenchymal ER $a$ does not inhibit p63 expression, and thus the normal squamous differentiation of cervicovaginal epithelium occurs (Kurita et al., 2004).

\section{Conclusions}

The importance of the interaction of the stroma or its embryonic/fetal precursor, mesenchyme, with epithelia in the differentiation, growth, and morphogenesis of many organs has been well documented. The data presented here emphasize that stromal-epithelial interactions also play a critical role in the hormonal response of epithelial cells of male and female reproductive tracts and mammary glands. A complete understanding of the actions of hormones on their respective target organs requires a determination of the mechanism by which the stroma and epithelium normally communicate with each other and how this pattern of communication is altered by hormonal binding to stromal versus epithelial receptors. The experimental systems described here utilize tissue from gene knockout mice in conjunction with tissue separation/recombination and provide potentially valuable tools to investigate the respective roles of epithelial versus stromal hormone receptors, which is critical for understanding of the mechanisms by which hormones regulate epithelial growth, differentiation, and function. Finally, the paracrine mediators that are involved in these regulatory cell-cell interactions need to be elucidated. A variety of growth factors have been implicated as paracrine mediators.

\section{References}

Bigsby RM: Control of growth and differentiation of the endometrium: the role of tissue interactions. Ann NY Acad Sci 955: 110-117; discussion 118, 396-406 (2002).

Bigsby RM, Caperell-Grant A, Berry N, Nephew K, Lubahn D: Estrogen induces a systemic growth factor through an estrogen receptor-alpha-dependent mechanism. Biol Reprod 70: 178-183 (2004).

Bocchinfuso WP, Korach KS: Mammary gland development and tumorigenesis in estrogen receptor knockout mice. J Mammary Gland Biol Neoplasia 2: 323-334 (1997).

Buchanan DL, Kurita T, Taylor JA, Lubahn DL, Cunha GR, Cooke PS: Role of stromal and epithelial estrogen receptors in vaginal epithelial proliferation, stratification and cornification. Endocrinology 139: 4345-4352 (1998a).

Buchanan DL, Setiawan T, Lubahn DL, Taylor JA, Kurita T, Cunha GR, Cooke PS: Tissue compartment-specific estrogen receptor participation in the mouse uterine epithelial secretory response. Endocrinology 140: 484491 (1998b).

Buchanan DL, Sato T, Peterson RE, Cooke PS: Antiestrogenic effects of 2,3,7,8-tetrachlorodibenzo-p-dioxin in mouse uterus: critical role of the aryl hydrocarbon receptor in stromal tissue. Toxicol Sci 57: 302-311 (2000).

Chang WY, Prins GS: Estrogen receptor-beta: implications for the prostate gland. Prostate 40: 115-124 (1999).

Cooke PS, Young P, Cunha GR: Androgen receptor expression in developing male reproductive organs. Endocrinology 128: 2867-2873 (1991).

Cooke PS, Buchanan D, Young P, Setiawan T, Brody J, Korach K, Taylor J, Lubahn D, Cunha GR: Stromal estrogen receptors (ER) mediate mitogenic effects of estradiol on uterine epithelium. Proc Natl Acad Sci USA 94: 6535-6540 (1997). 
Cooke PS, Buchanan DL, Lubahn DB, Cunha GR: Mechanism of estrogen action: lessons from the ERKO mouse. Biol Reprod 59: 470-475 (1998).

Couse JF, Curtis SW, Washburn TF, Lindzey J, Golding TS, Lubahn DB, Smithies O, Korach KS: Analysis of transcription and estrogen insensitivity in the female mouse after targeted disruption of the estrogen receptor gene. Mol Endocrinol 9: 1441-1454 (1995).

Couse JF, Korach KS: Estrogen receptor null mice: what have we learned and where will they lead us? Endocr Rev 20: 358-417 (1999).

Couse JF, Dixon D, Yates M, Moore AB, Ma L, Maas R, Korach KS: Estrogen receptor-alpha knockout mice exhibit resistance to the developmental effects of neonatal diethylstilbestrol exposure on the female reproductive tract. Dev Biol 238: 224-238 (2001).

Cunha GR: Stromal induction and specification of morphogenesis and cytodifferentiation of the epithelia of the Mullerian ducts and urogenital sinus during development of the uterus and vagina in mice. J Exp Zool 196: 361370 (1976).

Cunha GR, Lung B: The possible influences of temporal factors in androgenic responsiveness of urogenital tissue recombinants from wild-type and androgen-insensitive (Tfm) mice. J Exp Zool 205: 181-194 (1978).

Cunha GR, Donjacour AA, Cooke PS, Mee S, Bigsby RM, Higgins SJ, Sugimura Y: The endocrinology and developmental biology of the prostate. Endocr Rev 8: 338-362 (1987).

Cunha GR, Young P: Inability of Tfm (testicular feminization) epithelial cells to express androgen-dependent seminal vesicle secretory proteins in chimeric tissue recombinants. Endocrinology 128: 3293-3298 (1991).

Cunha GR, Alarid ET, Turner T, Donjacour AA, Boutin EL, Foster BA: Normal and abnormal development of the male urogenital tract: Role of androgens, mesenchymal-epithelial interactions and growth factors. J Androl 13: 465-475 (1992).

Cunha GR, Young P, Hom YK, Cooke PS, Taylor JA, Lubahn DB: Elucidation of a role of stromal steroid hormone receptors in mammary gland growth and development by tissue recombination experiments. J Mammary Gland Biol Neoplasia 2: 393-402 (1997).

Cunha GR, Donjacour AA, Hayward SW: Reciprocal mesenchymal-epithelial interactions in development of the male urogenital tract. In: Reproductive and developmental toxicology (Korach, KS, ed), Marcell Dekker Inc., 1998 (p. 509-530).

Donjacour AA, Cunha GR: Assessment of prostatic protein secretion in tissue recombinants made of urogenital sinus mesenchyme and urothelium from normal or androgeninsensitive mice. Endocrinology 131: 2342-2350 (1993).
Dupont S, Krust A, Gansmuller A, Dierich A, Chambon P, Mark M: Effect of single and compound knockouts of estrogen receptors alpha (ERalpha) and beta (ERbeta) on mouse reproductive phenotypes. Development 127 : 4277-4291 (2000).

Dürnberger H, Kratochwil K: Specificity of tissue interaction and origin of mesenchymal cells in the androgen response of the embryonic mammary gland. Cell 19: 465-471 (1980).

Forsberg JG: Animal model of human disease: adenosis and clear-cell carcinomas of vagina and cervix. Am J Pathol 84: 669-672 (1976).

Forsberg JG, Kalland T: Neonatal estrogen treatment and epithelial abnormalities in the cervicovaginal epithelium of adult mice. Cancer Res 41: 721-734 (1981).

Gallo MA, Hesse EJ, Macdonald GJ, Umbreit TH: Interactive effects of estradiol and 2,3,7,8-tetrachlorodibenzo-pdioxin on hepatic cytochrome P-450 and mouse uterus. Toxicol Lett 32: 123-132 (1986).

Gierthy JF, Bennett JA, Bradley LM, Cutler DS: Correlation of in vitro and in vivo growth suppression of MCF-7 human breast cancer by 2,3,7,8-tetrachlorodibenzo-pdioxin. Cancer Res 53: 3149-3153 (1993).

He WW, Kumar MV, Tindall DJ: A frameshift mutation in the androgen receptor gene causes complete androgen insensitivity in the testicular-feminized mouse. Nucleic Acids Res. 19: 2373-2378 (1991).

Herbst AL, Ulfelder H, Poskanzer DC: Adenocarcinoma of the vagina: Association of maternal stilbestrol therapy with tumor appearance in young women. New Eng J Med 284: 878-881 (1971).

Heuberger B, Fitzka I, Wasner G, Kratochwil K: Induction of androgen receptor formation by epithelium-mesenchyme interaction in embryonic mouse mammary gland. Proc Natl Acad Sci USA 79: 2957-2961 (1982).

Holcomb M, Safe S: Inhibition of 7,12-dimethylbenzanthracene-induced rat mammary tumor growth by $2,3,7,8$ tetrachlorodibenzo-p-dioxin. Cancer Lett 82: 43-47 (1994).

Kratochwil K, Schwartz P: Tissue interaction in androgen response of embryonic mammary rudiment of mouse: Identification of target tissue of testosterone. Proc Natl Acad Sci USA 73: $4041-4044$ (1976).

Kratochwil K: Development and loss of androgen responsiveness in the embryonic rudiment of the mouse mammary gland. Dev Biol 61: 358-365 (1977).

Kratochwil K: Tissue combination and organ culture studies in the development of the embryonic mammary gland. In: Developmental biology: A comprehensive synthesis (Eds, ed), Plenum Press, 1987 (p. 315-334).

Krege JH, Hodgin JB, Couse JF, Enmark E, Warner M, Mahler JF, Sar M, Korach KS, Gustafsson JA, Smithies 
O: Generation and reproductive phenotypes of mice lacking estrogen receptor beta. Proc Natl Acad Sci USA 95: 15677-15682 (1998).

Kuiper GG, Enmark E, Pelto-Huikko M, Nilsson S, Gustafsson JA: Cloning of a novel receptor expressed in rat prostate and ovary. Proc Natl Acad Sci USA 93: 5925-5930 (1996).

Kurita T, Young P, Brody J, Lydon JP, O'Malley BW, Cunha GR: Stromal progesterone receptors mediate the inhibitory effects of progesterone on estrogen-induced uterine epithelial cell (UtE) proliferation. Endocrinology 139: 4708-4713 (1998).

Kurita T, Lee K-J, Cooke PS, A. TJ, Lubahn DB, Cunha GR: Paracrine regulation of epithelial progesterone receptor by estradiol in the mouse female reproductive tract. Bio Reprod 62: 821-830 (2000a).

Kurita T, Lee K-J, Cooke PS, Lydon JP, Cunha GR: Paracrine regulation of epithelial progesterone receptor and lactoferrin by progesterone in the mouse uterus. Biol Reprod 62: 831-838 (2000b).

Kurita T, Cooke PS, Cunha GR: Epithelial-stromal tissue interaction in paramesonephric (Müllerian) epithelial differentiation. Dev Biol 240: 194-211 (2001a).

Kurita T, Cunha GR: Roles of p63 in differentiation of Mullerian duct epithelial cells. Ann N Y Acad Sci 948: 912 (2001).

Kurita T, Wang Y-Z, Donjacour AA, Zhao C, Lydon JP, O'Malley BP, Isaacs JT, Dahiya R, Cunha GR: Paracrine regulation of apoptosis by steroid hormones in the male and female reproductive system. Cell Death Differ 8: 192-200 (2001b).

Kurita T, Mills AA, Cunha GR: Roles of p63 in the diethylstilbestrol-induced cervicovaginal adenosis. Development 131: 1639-1649 (2004).

Lau KM, Leav I, Ho SM: Rat estrogen receptor-alpha and beta, and progesterone receptor mRNA expression in various prostatic lobes and microdissected normal and dysplastic epithelial tissues of the Noble rats. Endocrinology 139: 424-427 (1998).

Lejeune B, Van Hoeck J, Leroy F: Transmitter role of the luminal uterine epithelium in the induction of decidualization in rats. J Reprod Fertil 61: 235-240 (1981).

Lin TM, Ko K, Moore RW, Simanainen U, Oberley TD, Peterson RE: Effects of aryl hydrocarbon receptor null mutation and in utero and lactational 2,3,7,8-tetrachlorodibenzo-p-dioxin exposure on prostate and seminal vesicle development in C57BL/6 mice. Toxicol Sci 68: 479-487 (2002).

Lubahn DB, Moyer JS, Golding TS, Couse JF, Korach KS, Smithies O: Alteration of reproductive function but not prenatal sexual development after insertional disruption of the mouse estrogen receptor gene. Proc Natl Acad Sci
USA 90: 11162-11166 (1993).

Lydon JP, DeMayo FJ, Funk CR, Mani SK, Hughes AR, Montgomery CA, Shyamala G, Conneely OM, O'Malley BW: Mice lacking progesterone receptor exhibit pleiotropic reproductive abnormalities. Genes Dev 9: 2266-2278 (1995).

Lydon JP, DeMayo FJ, Conneely OM, O'Malley BW: Reproductive phenotypes of the progesterone receptor null mutant mouse. J Steroid Biochem Mol Biol 56: 6777 (1996).

Marker PC, Donjacour AA, Dahiya R, Cunha GR: Hormonal, cellular, and molecular control of prostatic development. Dev Biol 253: 165-174 (2003).

Martin L, Das R, Finn C: The inhibition by progesterone of uterine epithelial proliferation in the mouse. $J$ Endocr 57: 549 (1973).

McLachlan JA, Newbold RR, Bullock BC: Long-term effects on the female mouse genital tract associated with prenatal exposure to diethylstilbestrol. Cancer Res 40: 3988-3999 (1980).

Mueller SO, Clark JA, Myers PH, Korach KS: Mammary gland development in adult mice requires epithelial and stromal estrogen receptor alpha. Endocrinology 143: 2357-2365 (2002).

Murakami R, Shughrue PJ, Stumpf WE, Elger W, Schulze PE: Distribution of progestin-binding cells in estrogentreated and untreated neonatal mouse uterus and oviduct: autoradiographic study with [125I]progestin. Histochemistry 94: 155-159 (1990).

Ohno S: Major sex determining genes. Springer-Verlag. New York, 1979.

Ohta Y, Sato T, Iguchi T: Immunocytochemical localization of progesterone receptor in the reproductive tract of adult female rats. Biol Reprod 48: 205-213 (1993).

Pentecost BT, Newbold RR, Teng CT, McLachlan JA: Prenatal exposure of male mice to diethylstilbestrol alter the expression of the lactotransferrin gene in seminal vesicles. Mol Endocrinol 2: 1243-1248 (1988).

Plapinger L, Bern HA: Adenosis-like lesions and other cervicovaginal abnormalities in mice treated perinatally with estrogen. J Natl Cancer Inst 63: 507-518 (1979).

Prins GS, Marmer M, Woodham C, Chang W, Kuiper G, Gustafsson JA, Birch L: Estrogen receptor-beta messenger ribonucleic acid ontogeny in the prostate of normal and neonatally estrogenized rats. Endocrinology 139: 874-883 (1998).

Risbridger G, Wang H, Frydenberg M, Cunha GR: The metaplastic effects of estrogen on prostate epithelium: Proliferation of cells with basal cell phenotype. Endocrinology 142: 2443-2450 (2001a).

Risbridger G, Wang H, Young P, Kurita T, Wong Y, Lubahn D, Gustafsson J-A, Cunha G: Evidence that 
epithelial and mesenchymal estrogen receptor-a mediates effects of estrogen on prostatic epithelium. Dev Biol 229: 432-442 (2001b).

Robboy SJ, Szyfelbein WM, Goellner JR, Kaufman RH, Taft PD, Richard RM, Gaffey TA, Prat J, Virata R, Hatab PA, McGorray SP, Noller KL, Townsend D, Labarthe D, Barnes AB: Dysplasia and cytologic findings in 4,589 young women enrolled in diethylstilbestroladenosis (DESAD) project. Am J Obstet Gynecol 140: 579-586 (1981).

Schmidt JV, Su GH, Reddy JK, Simon MC, Bradfield CA: Characterization of a murine Ahr null allele: involvement of the Ah receptor in hepatic growth and development. Proc Natl Acad Sci USA 93: 6731-6736 (1996).

Sugimura Y, Cunha GR, Bigsby RM: Androgenic induction of deoxyribonucleic acid synthesis in prostatic glands induced in the urothelium of testicular feminized (Tfm/y) mice. Prostate 9: 217-225 (1986).
Sundstrom SA, Komm BS, Ponce-de-Leon H, Yi Z, Teuscher C, Lyttle CR: Estrogen regulation of tissuespecific expression of complement C3. J Biol Chem 264: 16941-16947 (1989).

Takeda H, Nakamoto T, Kokontis J, Chodak GW, Chang $\mathrm{C}$ : Autoregulation of androgen receptor expression in rodent prostate: immunohistochemical and in situ hybridization analysis. Biochem Biophys Res Commun 177: 488-496 (1991).

Tibbetts TA, Mendoza-Meneses M, O’Malley BW, Conneely OM: Mutual and intercompartmental regulation of estrogen receptor and progesterone receptor expression in the mouse uterus. Biol Reprod 59: 1143-1152 (1998).

Yang A, Kaghad M, Wang Y, Gillett E, Fleming MD, Dotsch V, Andrews NC, Caput D, McKeon F: p63, a p53 homolog at 3q27-29, encodes multiple products with transactivating, death-inducing, and dominant-negative activities. Mol Cell 2: 305-316 (1998). 